\title{
LIVED BODY vs GENDER: REFLEGTIONS ON SOCIAL STRUCTURE AND SUBJECTIVITY
}

\author{
Iris Marion Young
}

\section{Abstract}

Toril Moi has argued that recent deconstructive challenges to the concept of gender and to the viability of the sex/gender distinction have brought feminist and queer theory to a place of increasing theoretical abstraction. She suggests that we should abandon the category of gender once and for all, because it is founded on a nature-culture distinction and it tends incorrigibly to essentialize women's lives. Moi argues that feminist and queer theories should replace the concept of gender with a concept of the lived body derived from existential phenomenology. In this essay I take up and develop this suggestions, and argue that there are several advantages that a category of the lived body has over a category of gender for feminist and queer theories: (1) no nature-culture distinction is necessary but the body can be described as historically and socially specific; (2) it is not necessary to break out a gendered and "raced" part of identity with this category; (3) differences of sexual desire can be described without recourse to an "inner core" of identity or "sexual orientation." I go on to argue, however, that it is important to retain a concept of gender for a theoretical purpose beyond that which Moi and those she criticizes conceive. In recent years feminist and queer theories have tended to conceive their theorizing as restricted to identity and subjectivity. How large scale social structures differentially position people in relations of privilege and disadvantage has been ignored, relatively. This essay argues then that theorizing structural processes and inequalities is crucial, and that a concept of gender is important for such theorizing. I propose three aspects of gendered social structure that are irreducible to one another: (1) a sexual division of labor (2) normative heterosexuality, and (3) hierarchies of power. In each case I illustrate the social theoretical work these categorizations of gendered structure can and should do.

In her thorough and provocative essay, 'What Is a Woman?' Toril Moi argues that recent feminist and queer theorizing has brought us to the end of a constructivist gender rope. ${ }^{1}$ While feminist

${ }^{1}$ Toril Moi, 'What is a Woman?', in What is a Woman and Other Essays (Oxford: Oxford University Press, 2001). 
theory of the 1970's found a distinction between sex and gender liberating both for theory and practice, subsequent feminist and queer critiques have rightly questioned the distinction. By destabilizing categories both of biological sex and gender identity, recent deconstructive approaches to feminist and queer theorizing have opened greater possibilities for thinking a plurality of intersecting identities and practices. Deconstructive challenge to the sex/gender distinction has increasingly abstracted from embodiment, however, at the same time that it has rendered a concept of gender virtually useless for theorizing subjectivity and identity. At this theoretical pass, Moi proposes that we throw over the concept of gender altogether and renew a concept of the lived body derived from existential phenomenology, as a means of theorizing sexual subjectivity without danger either of biological reductionism or gender essentialism.

Moi is not alone in proposing that feminist and queer theory question the usefulness of a concept of gender even more deeply than have deconstructive critiques, and I will refer to other recent writings that make similar points in the course of my discussion. I concentrate on Moi because her analysis of the evolution of our troubles with gender is so thorough, and because I find attractive her proposal that feminist and queer theory adopt a concept of the lived body to do the work that she argues that the category of gender does not do well. I find Moi's argument incomplete, however. While she is correct that gender is a problematic concept for theorizing subjectivity, there are or ought to be other aspects of feminist and queer theorizing that cannot do without a concept of gender. By reflecting on Moi's account of recent feminist and queer theorizing, we discover that these aspects, which concern social structure more than subjectivity and identity, have been relatively neglected. The oppression of women and people who transgress heterosexual norms occurs through systemic processes and social structures which need description that uses different concepts from those appropriate for describing subjects and their experience. Moi's proposal to reconstitute a concept of the lived body helps for the latter, but for the former we need a reconstituted concept of gender.

\section{The sex-gender distinction}

Early feminist appropriations of what until then had been an obscure psychological distinction between gender, as referring to 
self-conception and behaviour, and sex, as referring to anatomy and physiology, were very theoretically and politically productive. At this theoretical moment challenging the conviction that 'biology is destiny' was an important feminist project. In order to argue for opening wider opportunities for women, we needed ways to conceptualize capacities and dispositions of members of both sexes that distanced behaviour, temperament, and achievement from biological or natural explanations. A distinction between sex and gender served this purpose. Feminists could affirm that of course men and women are 'different' in physique and reproductive function, while denying that these differences have any relevance for the opportunities members of the sexes should have or the activities that they should engage in. Such gender rules and expectations are socially constituted and socially changeable. Much of this early second wave feminist theorizing invoked an ideal of equality for women that envisioned an end to gender. 'Androgyny' named the ideal that many feminists theorized, a social condition in which biological sex would have no implications for a person's life prospects, or the way people treated one another (including, importantly, in the most consistent of these theories, one's choice of sex partners). These androgynous persons in the transformed liberated society would have no categorically distinct forms of dress, comportment, occupations, propensities toward aggression or passivity, associated with their embodiment. We would all be just people with various bodies. $^{2}$

This appeal to an ideal of androgyny was short lived. Some of the turning point texts of feminist theory in the late 1970's and early 1980's turned instead to accounts of the social and psychological specificities of femininely gendered identity and social perspective derived from gender roles. While not at all explained by biological distinctions between men and women, nevertheless there are deep social divisions of masculine and feminine gendered dispositions and experience which have implications for the psychic lives of men and women, their interactions with one another, their dispositions to care for children or exercise authority. Nancy Chodorow, Carol Gilligan, Nancy Hartsock and others developed theories of feminine gender identities as

${ }^{2}$ For one statement of the androgynous ideal, see Ann Ferguson, 'Androgyny as an Ideal for Human Development', in Sexual Democracy: Women, Oppression and Revolution (Westview: Allen and Unwin, 1991). 
expressing a general structure of subjectivity and social standpoint in significant ways defining the lives and possibilities of most women. ${ }^{3}$

No sooner had such a general account of feminine gender identity emerged than it came under attack as 'essentialist'. These accounts assume mothering as defining the experience of most women. They fail to inquire about the differences that race or class positioning make to caring practices, and they assume that women are or wish to be in relationships with men. They extrapolate from the historical specificity of twentieth century affluent urban nuclear families and occupations structures, ignoring historical and cross-cultural specifications in the organization of family and work. Although the criticisms were not always voiced in the fairest way, most feminist theorists took their points to heart.

Queer theory broke into this dissolution of gender theory, in the person of writers such as Diana Fuss and Judith Butler. Because Moi focuses on Butler's subversion of the sex-gender distinction, and I will support Moi's conclusion in specific respects, I will follow Moi in this focus.

In Gender Trouble, Butler questioned the motive of feminist theory to seek a theory of gender identity. Feminists believe they need such a general theory of gender, she argued, in order to know what is the subject of feminist politics. Feminism has no meaning as a specific transformative social movement, it is thought, without an account of the 'agent' of change, the subject to be liberated; that subject is 'woman', and 'gender' is the concept that displays what a woman is. As gendered, 'women' are distinct from the biological sex, female. Butler argued, however, that the feminist distinction between sex and gender nevertheless retains a binarism of stable categorical complementarity between male and female, which reproduces a logic of heterosexual normativity. The very distinction between sex and gender ought to be put in question in order to challenge any reliance on a distinction between nature and culture, or any conception that subjects have inner lives to which an idea of stable gender identity corresponds. Gender is nothing other than a social performative. The discursive rules of normative heterosexuality

${ }^{3}$ Nancy Chodorow, The Reproduction of Mothering (Berkeley: University of California Press, 1978; 2n edition 1999); Carol Gilligan, In a Different Voice (Cambridge: Harvard University Press, 1982); Nancy C. M. Hartsock, Money, Sex and Power: Toward a Feminist Historical Materialism (Notheastern University Press, 1983). 
produce gendered performances that subjects reiterate and cite; the sexing of bodies themselves derives from such performatives. In this process of reiterated gender performance some persons become constituted as abject, outside the heterosexual binary. Radical politics, then, consists in troubling the gender binaries and playing with gender citation.

In response to the critical reaction of some commentators that her theory of gender as performance makes bodies and sexual identity simply a product of discourse, in Bodies That Matter Butler argues that the materiality of sexed bodies is itself socially constituted. She insists that such production of bodies is not 'idealist', and that a valuation of 'materialism' over 'idealism' itself relies on a questionable binary logic.

Moi does not refute Butler's arguments, which she takes to be cogent, given their terms and methods. She argues nevertheless that ideals of subjectivity and sexuality have become increasingly abstract in this train of theorizing that begins with the sex-gender distinction and ends deconstructing a material-ideal dichotomy. It is not clear at this point what lived problems the theory addresses or how the concepts help people understand and describe their experience. Butler successfully calls into question the logic of the sex-gender distinction, yet her theorizing never goes beyond these terms and remains tied to them. This line of critique, Moi argues, calls for throwing off the idea of gender altogether as useful for understanding subjectivity and identity. Queer theory and practice bend gender meanings, aiming to loosen them from the normative polarities of hegemonic masculinity and femininity. Moi suggests that queer and feminist theorists should make a break with gender altogether.

\section{The lived body}

For an alternative to the categories of sex and gender, Moi proposes to return to the framework of existential phenomenology on which Simone de Beauvoir relies. ${ }^{4}$ The central category for

${ }^{4}$ Sonia Kruks gives a reading of the existentialism of Simone de Beauvoir that aims to respond to contemporary conundrums of 'identity politics' in feminist theory. She too proposes to understand Beauvoir as developing a concept of the lived body useful for feminist theory, and she argues that interpretations of Beauvoir have failed to appreciate the extent to which she was influenced by Maurice Merleau-Ponty's concept of the lived body; see Kruks, 'Freedoms that Matter: Subjectivity and Situation in the Work of Beauvoir, Sartre and Merleau-Ponty', in Kruks, Retrieving Experience: Subjectivity and Recognition in Feminist Politics (Ithaca: Cornell University Press, 2001), pp. 27-51. Debra B. Bergoffen also 
this theoretical approach is that of the lived body. A reconstituted concept of the lived body, Moi argues, would offer feminists an idea that can serve the function we have wanted from the sexgender categorization, without bringing its problems.

The lived body is a unified idea of a physical body acting and experiencing in a specific socio-cultural context; it is body-in-situation. For existentialist theory, situation denotes the produce of facticity and freedom. The person always faces the material facts of her body and its relation to a given environment. Her bodily organs have certain feeling capacities and function in determinate ways; her size, age, health and training make her capable of strength and movement in relation to her environment in specific ways. Her skin has a particular colour, her face determinate features, her hair particular colour and texture, each with their own aesthetic properties. Her specific body lives in a specific context - crowded by other people, anchored to the earth by gravity, surrounded by buildings and streets with a unique history, hearing particular languages, having food and shelter available, or not, as a result of culturally specific social processes that make specific requirements on her to access them. All these concrete material relations of a person's bodily existence and her physical and social environment constitute her facticity.

The person, however, is an actor; she has an ontological freedom to construct herself in relation to this facticity. The human actor has specific projects, things she aims to accomplish, ways she aims to express herself, make her mark on the world, transform her surroundings and relationships. Often these are projects she engages in jointly with others. Situation, then, is the way that the facts of embodiment, social and physical environment appear in light of the projects a person has. She finds that her movements are awkward in relation to her desire to dance. She sees the huge city with its thousand year history as an opportunity for learning about her ancestors. 'To claim that the body is a situation is to acknowledge that the meaning of a woman's body is bound up with the way she uses her freedom' (Moi, p. 65).

How does Moi propose that the idea of the lived body might replace that of gender, and the distinction between sex and

recommends a return to Simone de Beauvoir as a way out of conundrums of gender theorizing to which recent feminist and queer theories have come. See Bergoffen, 'Simone de Beauvoir: Disrupting the Metonymy of Gender', in Dorothea Olkowski, ed., Resistance, Flight, Creation: Feminist Enactments of French Philosophy (Ithaca: Cornell University Press, 2000), pp. 97-119. 
gender? Like the category of sex, that of the lived body can refer to the specific physical facts of bodies, including sexual and reproductive differentiation. 'Woman' and 'man' name the physical facticity of certain bodies, some with penises, others with clitorises and breasts, each with differing experiences of desire and sexual feeling. A category of lived body, moreover, need not make sexual difference dimorphous; some bodies have physical traits like those of men in certain respects and those of women in others. People experience their desires and feeling in diverse ways that do not neatly correlate with sexual dimorphism or heterosexual norms. As a lived body, moreover, perceptual capacities and motility are not distinct from association with sexual specificity; nor is size, bone structure or skin colour. Most important for the proposal Moi makes, the concept of the lived body, unlike the concept of sex, is not biologistic. It does not refer to an objectivist scientific account that generalizes laws of physiology and function. A scientific approach to bodies proceeds at a significantly higher level of abstraction than does a description of bodies as lived. The idea of the lived body thus can bring the physical facts of different bodies into theory without the reductionist and dichotomous implications of the category of 'sex'.

The idea of the lived body, moreover, refuses the distinction between nature and culture that grounds a distinction between sex and gender. The body as lived is always enculturated: by the phonemes a body learns to pronounce at a very early age, by the clothes the person wears that mark her nation, her age, her occupational status, and in what is culturally expected or required of women. The body is enculturated by habits of comportment distinctive to interactional settings of business or pleasure; often they are specific to locale or group. Contexts of discourse and interaction position persons in systems of evaluation and expectations which often implicate their embodied being; the person experiences herself as looked at in certain ways, described in her physical being in certain ways, she experiences the bodily reactions of others to her, and she reacts to them. The diverse phenomena that have come under the rubric of 'gender' in feminist theory can be redescribed in the idea of lived body as some among many forms of bodily habitus and interactions with others that we enact and experience. In such redescription we find that Butler is right in at least this respect: it is a mystification to attribute the ways of being associated with the category 'gender' to some inner core of identity of a subject, whether understood as 'natural' or acquired. 
In a recent essay Linda Nicholson similarly proposes that feminist and queer theory focus on the socio-historically differentiation of bodies as lived, rather then maintain a distinction between biological sex and embodiment and gender as historically variable. To the extent that this distinction between sex and gender remains, feminist theory continues a 'biological foundationalism', as distinct from biological reductionism. The study of sexuality, reproduction and the roles assigned to men and women should consist in reading bodies themselves and not presume a nature/culture distinction that considers gender as "merely cultural'. ${ }^{5}$

The idea of the lived body thus does the work the category 'gender' has done, but better and more. It does this work better because the category of the lived body allows description of the habits and interactions of men with women, women with women, and men with men in ways that can attend to the plural possibilities of comportment, without necessary reduction to the normative heterosexual binary of 'masculine' and 'feminine'. It does more because it helps avoid a problem generated by use of ascriptive general categories such as 'gender,' 'race,' 'nationality,' 'sexual orientation', to describe the constructed identities of individuals, namely the additive character that identities appear to have under this description. If we conceptualize individual identities as constituted by the diverse group identities - gender, race, class, sexual orientation, and so on - there seems to be a mystery both about how persons are individualized, and how these different group identities combine in the person. With the idea of the lived body there is no such puzzle. Each person is a distinctive body, with specific features, capacities, and desires, that are similar to and different from those of others in determinate respects. She is born in a particular place and time, is raised in a particular family setting, and all these have specific socio-cultural histories that stand in relation to the history of others in particular ways. What we call categories of gender, race, ethnicity, etc. are short hand for a set of structures that position persons, a point to which I will return. They are not properly theorized as general group identities that add together to constitute individual identities. The individual person lives out her unique body in a socio-historical context of the behaviour and expectations of others, but she does

Linda Nicholson, 'Interpreting Gender', The Play of Reason: From the Modern to the Postmodern (Ithaca: Cornell University Press, 1999), pp. 53-76.

(C) Blackwell Publishers Ltd. 2002 
not have to worry about constituting her identity from a set of generalized 'pop-beads' strung together. ${ }^{6}$

By means of a category of the lived body, then, 'One can arrive at a highly historicized and concrete understanding of bodies and subjectivity without relying on the sex-gender distinction that Butler takes as axiomatic' (Nicholson 1999, p. 46). The idea of the lived body recognizes that a person's subjectivity is conditioned by socio-cultural facts and the behaviour and expectations of others in ways that she has not chosen. At the same time, the theory of the lived body says that each person takes up and acts in relation to these unchosen facts in her own way.

To consider the body as a situation . . . is to consider both the fact of being a specific kind of body and the meaning that concrete body has for the situated individual. This is not the equivalent of either sex or gender. The same is true for 'lived experience' which encompasses our experience of all kinds of situations (race, class, nationality, etc.) and is a far more wideranging concept than the highly psychologizing concept of gender identity (Nicholson 1999, p. 81).

\section{Is the lived body enough?}

Toril Moi argues that a concept of the lived body serves feminist theoretical purposes better than a concept of gender. She defines those purposes as providing a theory of subjectivity and the body, and providing an understanding of what it means to be a woman or man in a particular society (pp. 4, 36, 14). Feminist theory, she says, ought to become a project of dispelling confusions concerning bodies, sex, sexuality, sexual difference, and the power relations among women and men, heterosexuals and homosexuals (p. 120). This last phrase about power relations is extremely vague. Depending on how it is specified, the scope of theorizing power relations might fall beyond what I take as Moi's major emphasis in defining the tasks of feminist theory. She defines this theory as focusing on subjectivity, who one is as an agent, the attributes and capacities one has for experience, the relations with others that contribute to one's sense of self. In the essay I referred to earlier, Linda Nicholson also seems to consider that the theoretical function that a concept of gender has meant to

${ }^{6}$ See Elizabeth Spelman, Inessential Woman: Problems of Exclusion in Feminist Thought (Boston: Beacon Press, 1988). 
serve is that of theorizing self-identity and the social constitution of the human character.

Recent discussions questioning the stability of gender and the adequacy of a sex-gender distinction reveal dilemmas and increasing abstraction into which feminist and queer theory has either been forced or has had to respond to. These problems with a concept of gender have surfaced at least partly because gender aims to be a general category, but subjectivity is always particular. Moi's appropriation of the concept of the lived body offers more refined tools for theorizing sexed subjectivity, and the experience of differently situated men and women than does the more blunt category of gender. Agreeing with this means dispensing with gender altogether, however, only if the projects of feminist and queer theories consist only in theorizing subjectivity. But I think they are not. The debates about gender and essentialism that Moi aims to bring to a close with her arguments have, I think, tended to narrow the interests of feminists and queer theorists to issues of experience, identity and subjectivity. Her discussion clears the way for asking whether other aspects of a project for feminist and queer theory have been obscured by these debates, for which a resituated concept of gender might still be needed. In the remaining pages of this essay I want to suggest that a concept of gender is important for theorizing social structures and their implications for the freedom and well being of persons.

As I understand them, feminist and queer theory consist not only in giving account of the meaning of the lives of women and men in all their relational and sexual diversity. Nor is it only about analyzing how discourses construct subjects and the stereotypical or defamatory aspects of some of these discourses that contribute to the suffering of some men and women who fall on the wrong side of normalizing processes. Feminist and queer theories are also projects of social criticism. These are theoretical efforts to identify certain wrongful harms or injustices, locate and explain their sources in institutions and social relations, and propose directions for institutionally oriented action to change them. This latter set of tasks requires the theorist to have an account not only of individual experience, subjectivity, and identity, but also of social structures.

In other writings I have articulated a concept of social structure specifically directed at the project of giving institutional account of sources of injustice and in response to the dilemmas that 
emerge from claiming that individuals share group identities. ${ }^{7}$ Structures denote the confluence of institutional rules and interactive routines, mobilization of resources, and physical structures, which constitute the historical givens in relation to which individuals act, and which are relatively stable over time. Structures also connote the wider social outcomes that result from the confluence of many individual actions within given institutional relations, whose collective consequences often do not bear the mark of any person or group's intention.

Alexander Wendt distinguishes two levels or kinds of structure, micro and macro levels. Micro structures refer to structural analysis of interaction. The patterning of practices and interactive routines, the rules which actors implicitly or explicitly follow and the resources and instruments they mobilize in their interactions can all be regarded as structured. Gender structures are very important to interactions at this micro level. In recommending that feminist social theory complement attention to subjectivity and identity with renewed attention to social structures, however, I am more concerned with what Wendt refers to as the macro level, which involve 'multiply realizable outcomes' ${ }^{8}$ That is to say, social theory that wishes to understand and criticize the constraints on individuals and groups that render them relatively unfree and limited in their opportunities in relation to others need to have a picture of large-scale systemic outcomes of the operations of many institutions and practices which produce outcomes that constrain some people in specific ways at the same time that they enable others. Macro structures depend on microlevel interactions for their production and reproduction, according to Wendt, but their form and the ways they constrain and enable cannot be reduced to effects of particular interactions.

Social structures position individuals in relations of labour and production, power and subordination, desire and sexuality, prestige and status. The way a person is positioned in structures is as much a function of how other people treat him or her within various institutional settings as it is the attitude a person takes to

See Inclusion and Democracy (Oxford: Oxford University Press, 2000), especially Chapter 3; see also 'Equality of Whom? Social Groups and Judgments of Injustice', Journal of Political Philosophy, Vol. 9, no. 1, March 2001, pp. 1-18. There I build a definition of social structures by drawing primarily on ideas of Peter Blau, Anthony Giddens and Jean Paul Sartre.

${ }^{8}$ Alexander Wendt, Social Theory and International Relations (Cambridge: Cambridge University Press, 2000), Chapter 4. 
himself or herself. Any individual occupies multiple positions in structure, and these positionings become differently salient depending on the institutional setting and the position of others there.

From the point of view of critical social theory, the main reason to care about structures is in order to have an account of the constitution and causes of social inequality. Some people encounter relative constraints in their freedom and material well being as the cumulative effect of the possibilities of their social positions, as compared with others who in their social positions have more options or easier access to benefits. Social groups defined by caste, class, race, age, ethnicity, and, of course, gender, name subjective identities less than axes of such structural inequality. They name structural positions whose occupants are privileged or disadvantaged in relation to one another due to the adherence of actors to institutional rules and norms and the pursuit of their interests and goals within institutions. A structural account offers a way of understanding inequality of opportunity, oppression and domination, that does not seek individualized perpetrators, but rather considers most actors complicit in its production, to a greater or lesser degree.

Nancy Folbre conceptualizes such issues of social inequality in terms she calls 'structures of constraint.' ${ }^{9}$ Structures of constraint include sets of asset distributions, rules, norms and preferences that afford more freedom and opportunity for benefits to some than others. Constraints define the range of options available to individuals, or the costs of pursuing some options rather than others. Time and money are basic assets. Legal rules function as important constraints, but so do cultural norms. They impose a 'price' on nonconformity. Preferences can be constraints when they conflict with one another. A configuration of particular assets, rules, norms and preferences creates the constraints that define what we call social groups based on gender, class, race, age, and so on. Thus membership in the group called 'women' is the product of a loose configuration of different structural factors.

To describe and explain some of the structures and processes that produce differential opportunities and privileges in contemporary society, I suggest, we cannot do without a concept of gender. Feminist and queer theories need conceptual tools to

\footnotetext{
${ }^{9}$ Nancy Folbre, Who Pays for the Kids? (New York: Routledge, 1994 ), especially Chapter 2 .
} 
describe the rules and practices of institutions that presume differing roles for men and women, and/or which presume that men and women are coupled with each other in intimate relations. We need tools for understanding how and why certain patterns in the allocation of tasks or status recognition remain persistent in ways that limit the options of many women and of most people whose sexual and intimate choices deviate from heterosexual norms. An important conceptual shift occurs, however, when we understand the concept of gender as a tool for theorizing structures more than subjects. We no longer need to ascribe a single or shared gender identity to men and women.

My own effort to respond to critiques of early feminist theories of gender turned in this direction of theorizing gender as an attribute of social structures more than of persons. In 'Gender as Seriality: Thinking About Women as a Social Collective,' I draw on a concept from Sartre's later philosophy, his idea of a series. ${ }^{10}$ Gender, I suggest there, is best understood as a particular form of the social positioning of lived bodies in relation to one another within historically and socially specific institutions and processes that have material effects on the environment in which people act and reproduce relations of power and privilege among them. On this account, what it means to say that individual persons are 'gendered' is that we all find ourselves passively grouped according to these structural relations, in ways too impersonal to ground identity. There I proposed that there are two basic axes of gender structures: a sexual division of labour and normative heterosexuality. Here I will take a lead from Bob Connell and add to these a third axis, gendered hierarchies of power. ${ }^{11}$

The structuring of work and occupations by gender is a basic aspect of all modern societies (and many premodern societies), with far reaching consequences for the lives of individuals, the constraints and opportunities they face. The core of a gendered division of labour in modern societies is the division between 'private' and 'public' work. An aspect of the basic structure of these societies is that the work of caring - for persons, their bodily needs, their emotional well being, and the maintenance of their dwellings - takes place primarily in unpaid labour in private homes. While recent decades have seen some changes in the allo-

${ }^{10}$ In I.M. Young, Intersecting Voices: Dilemmas of Gender, Political Philosophy and Policy (Princeton: Princeton University Press, 1997).

${ }^{11}$ R. W. Connell, Gender and Power (Stanford: Stanford University Press, 1987). 
cation of this work between men and women, it is still the case that this unpaid caring and household work falls primarily to women. The operations of the entire society depend on the regular performance of this work, yet it goes relatively unnoticed and little valued. The persons to whom this work is assigned have less time and energy to devote to other tasks and activities than do those who do less of it. This gendered division of labour persists apparently because people collectively do not wish to organize broadly funded public services that take more collective responsibility for care work. Despite many significant changes in gender ideas and ideology in contemporary societies, there has been little change in this basic division of labour. Indeed, neo-liberal economic policies across the globe have had the effect of retrenching this division where it may have loosened.

Feminist social and political theory in the last twenty years has documented dozens of ways that this gendered structure constrains the opportunities of those persons doing unpaid care work, mostly women..$^{12}$ They work longer hours than others, and are rendered dependent on other people for provision of their needs, which makes them vulnerable to poverty or abuse. Feminist researchers have also documented how this basic structure underlies occupational divisions in public paid work according to gender. When occupations involve caring they tend to become female gendered. Because many women arrange their public work lives in relation to caring responsibilities, only a relatively small number of occupations welcome them, which helps keep wages low in those occupations. The structuring of both private and public work along these lines exhibits gendered hierarchies of status and power, not to mention financial reward.

It might be thought that these structural consequences of a sexual division of labour describe Western industrial societies primarily. Theorized at the right level of categorical generality, however, similar structures describe much about many less developed countries, especially in urban life. As some feminist scholars of development have argued, for example, both government policy and the policies of international organizations such as the International Monetary Fund implicitly rely on the assumption that unpaid domestic labour is infinitely expandable, and that

${ }^{12}$ Nancy Folbre's book, cited above, is an excellent analysis of the operations of these constraints in several countries in Europe, Asia and Latin America as well as the United States.

C C Blackwell Publishers Ltd. 2002 
household caretakers are available to take up the slack in meeting the needs of their family members when food subsidies are slashed, school fees go up, or health clinics are closed.

A structural account of the sexual division of labour, that is, does not assume that this division of labour has the same content across societies. It is a theoretical framework that asks whether there are tasks and occupations usually performed by members of one sex or the other, and/or whether the social norms and cultural products of the society tend to represent certain tasks or occupations as more appropriately performed by members of one sex or the other. For any society, both today and in the past, the answer is usually yes, but there is nevertheless considerable variation among them in which occupations are sex associated, the ideologies often legitimating these associations, how many tasks are sex typed, and what implications this sexual division of labour has for the distribution of resources among persons, their relative status, and the constraints and opportunities that condition their lives.

A second axis of gender structuring in our society is normative heterosexuality. This structuring consists in the diverse institutional and ideological facts that privilege heterosexual coupling. These include the form and implications of many legal institutions, many rules and policies of private organizations in allocating positions and benefits, the structuring of schooling and mainstream media to accord with these institutions, as well as the assumptions many people make in their everyday interactions with others. Together such social facts make structures with differential consequences on the lives of different men and women, and which sometimes produce serious suffering or wrongful limitations on freedom. The system of normative heterosexuality significantly constrains the lives of men and women, with all their varying sexual and desiring inclinations, motivating some to adjust their lives in ways they believe will bring them material reward and acceptance, and others to carve out lives in the interstices of social relations where their desires and projects do not fit, or openly rebel.

Cheshire Calhoun argues that lesbian and gay subordination is different in form from the structural constraints on the lives of women or people of colour, for example. Whereas structures of female subordination or institutionalized racism confine people perceived as belonging to certain categories as having certain places or positions, Calhoun argues that persons who transgress 
heterosexual norms have no legitimized place at all in political citizenship, civil society, or private spheres. Structures of normative heterosexuality constrain lesbians and gay men by enforcing their invisibility. ${ }^{13}$

An institutionalized valuation of particular associations of maleness or masculinity condition hierarchies of power in ways that constrain the possible actions of many people seem quite resistant to change. Positions and practices of institutionalized and organized violence are most important here - military and police forces, prison systems, etc. In general, the structuring of state institutions, corporations and other bureaucracies according to hierarchies of decision making authority and status afford some people significant privileges and freedom, and these are usually men, at the same time that they limit, constrain and subordinate others, including most women and many men. Gendered hierarchies of power intersect with a sexual division of labour and normative heterosexuality in many ways to reproduce a sense of entitlement of men to women's service and an association of heterosexual masculinity with force and command.

When describing social structures as gendered it is neither necessary to make generalizations about men and women nor is it necessary to reduce varying gender structures to a common principle. A gendered occupational division of labour may strongly code certain occupations as female and others as male, and these codings may have far reaching implications for the power, prestige and material reward incumbents of each enjoy. Nothing follows from this, however, about what most men or most women do for a living. Recognizing the structures of normative heterosexuality may well result in theorizing plural understandings of gender, varying rules and practices that make expectations on men and women regarding sexual interaction, relation of adults and children, social aesthetics, relationship of persons to workplace roles, and so on, that do not share a common logic and in some respects may be in tension with one another. Structures of a gendered hierarchy of power differentiate men from one another according to social roles and dispositions, and do not simply differentiate men and women. The most important thing about the analysis is to understand how the rules, relations and their material consequences produce privileges for some people

${ }^{13}$ Cheshire Calhoun, Feminism, the Family, and the Politics of the Closet: Lesbian and Gay Displacement (Oxford: Oxford University Press, 2000).

C Blackwell Publishers Ltd. 2002 
that underlie an interest in their maintenance, at the same time that they limit options of others, cause relative deprivations in their lives, or render them vulnerable to domination and exploitation.

In this essay I have agreed with Toril Moi's proposal that the existential phenomenological category of the lived body is a richer and more flexible concept than gender for theorizing the socially constituted experience of women and men than either concepts of sex or gender. The lived body is particular in its morphology, material similarities and differences from other bodies. I have argued, moreover, that this proposal should not mean dispensing with a category of gender, but rather confining its use to analysis of social structures for the purposes of understanding certain specific relations of power, opportunity and resource distribution. An obvious question arises at this point, as to the relation of lived bodies to these structures.

Another reason that turning to a concept of lived body may be productive for feminist and queer theory is precisely that it can offer a way of articulating how persons live out their positioning in social structures along with the opportunities and constraints they produce. I do not have the space here to develop the framework for such articulation, and I will offer only a few lines toward a sketch.

Gender structures, I said above, are historically given and condition the action and consciousness of individual persons. They precede that action and consciousness. Each person experiences aspects of gender structures as facticity, as socio-historical givens with which she or he must deal. Every person faces the question of what to wear, for example, and clothing options and conventions derive from multiple structures of profit seeking, class and occupational distinction, income distribution, heterosexual normativity, and spaces and expectations of occasions and activities and the possibilities of conformity and transgression they bring. However limited the choices or the resources to enact them, each person takes up the constrained possibilities that gender structures offer in their own way, forming their own habits as variations on those possibilities, or actively try to resist or refigure them. Gender as structured is also lived through individual bodies, always as personal experiential response and not as a set of attributes that individuals have in common

Pierre Bourdieu's concept of the habitus offers one interpretation of how generalized social structures are produced and repro- 
duced in the movement and interaction of bodies. Especially in his understanding of gender structures, however, Bourdieu's understanding of the relation of social structures to actors and experience conceptualizes these structures too rigidly and ahistorically. ${ }^{14}$ It may be more fruitful to draw on a theory of lived body like that of Maurice Merleau-Ponty, but connect it more explicitly than he does to how the body lives out its positions in social structures of the division of labour, hierarchies of power, and norms of sexuality. ${ }^{15}$ Under the influence of such a theory of how bodies live out their structured positioning, moreover, one might find that a deconstructive gender theory such as Judith Butler's appears not as a theory of the determination or constitution of gendered subjects, but as a theory of the variable movements of habituated bodies both reacting to, reproducing, and modifying structures.

\section{Political Science Department}

University of Chicago

Pick Hall, 5828 S. University Avenue

Chicago, IL 60637

USA

iyoung@uchicago.edu

\section{References}

Bergoffen, Debra, B. (2000). 'Simone de Beauvoir: Disrupting the Metonymy of Gender', in Dorothea Olkowski, ed., Resistance, Flight, Creation: Feminist Enactments of French Philosophy (Ithaca: Cornell University Press).

Bourdieu, Pierre. (1990). The Logic of Practice, Richard Nice, trans., (Stanford: Stanford University Press).

Bourdieu, Pierre. (1998). La Domination Masculine (Paris: Editions du Seuil)

Calhoun, Cheshire. (2000). Feminism, the Family, and the Politics of the Closet: Lesbian and Gay Displacement (Oxford: Oxford University Press).

${ }^{14}$ See for example, Pierre Bourdieu, The Logic of Practice, Richard Nice, trans., (Stanford: Stanford University Press, 1990), especially Chapters 3 and 4. Toril Moi herself explores the implications of Bourdieu's theory for feminist theory; see 'Appropriating Bourdieu: Feminist Theory and Pierre Bourdieu's Sociology of Culture,' Chapter 3 of What is a Woman? Bourdieu's book, La Domination Masculine (Paris: Editions du Seuil, 1998) assumes that he can generalize about gender structures largely from his observations of the Kabylic society in North Africa.

${ }^{15}$ Nick Crossley argues that a reconstruction of Merleau-Ponty's theory of sociality and habit can better serve social theory than Bourdieu's concept of habitus because MerleauPonty's conceptualization gives more place to freedom and individual difference. See Crossley, 'The Phenomenological Habitus and Its Construction,' Theory and Society Vol. 30, 2001, pp. 81-120; see also 'Habitus, Agency and Change: Engaging with Bourdieu,' paper presented at a conference on the Philosophy of the Social Science, Czech Academy of Sciences, Prague, May 2001. 
Chodorow, Nancy. (1978). The Reproduction of Mothering (Berkeley: University of California Press; 2nd edition 1999).

Connell, R. W. (1987). Gender and Power (Stanford: Stanford University Press).

Crossley, Nick. (2001). 'The Phenomenological Habitus and Its Construction,' Theory and Society Vol. 30, pp. 81-120.

Crossley, Nick. (2001). 'Habitus, Agency and Change: Engaging with Bourdieu,' paper presented at a conference on the Philosophy of the Social Science, Czech Academy of Sciences, Prague, May 2001.

Ferguson, Ann. (1991). 'Androgyny as an Ideal for Human Development', in Sexual Democracy: Women, Oppression and Revolution (Westview: Allen and Unwin).

Folbre, Nancy. (1994). Who Pays for the Kids? (New York: Routledge).

Gilligan, Carol. (1982). In a Different Voice (Cambridge: Harvard University Press).

Hartsock, Nancy, C. M. (1983). Money, Sex and Power: Toward a Feminist Historical Materialism (Northeastern University Press).

Kruks, Sonia. (2001). 'Freedoms that Matter: Subjectivity and Situation in the Work of Beauvoir, Sartre and Merleau-Ponty', in Kruks, Retrieving Experience: Subjectivity and Recognition in Feminist Politics (Ithaca: Cornell University Press).

Moi, Toril. (2001). 'Appropriating Bourdieu: Feminist Theory and Pierre Bourdieu's Sociology of Culture,' in What is a Woman?

Moi, Toril. (2001). 'What is a Woman?', in What is a Woman and Other Essays (Oxford: Oxford University Press).

Nicholson, Linda. (1999). 'Interpreting Gender', The Play of Reason: From the Modern to the Postmodern (Ithaca: Cornell University Press).

Spelman, Elizabeth. (1988). Inessential Woman: Problems of Exclusion in Feminist Thought (Boston: Beacon Press).

Wendt, Alexander. (2000). Social Theory and International Relations (Cambridge: Cambridge University Press).

Young, Iris, M. (1997). Intersecting Voices: Dilemmas of Gender, Political Philosophy and Policy (Princeton: Princeton University Press).

Young, Iris, M. (2000). Inclusion and Democracy (Oxford: Oxford University Press).

Young, Iris, M. (2001). 'Equality of Whom? Social Groups and Judgments of Injustice', Journal of Political Philosophy, Vol. 9, no. 1. 
Copyright of Ratio is the property of Wiley-Blackwell and its content may not be copied or emailed to multiple sites or posted to a listserv without the copyright holder's express written permission. However, users may print, download, or email articles for individual use. 